\title{
THE RELATIONSHIPS BETWEEN IT FLEXIBILITY, IT-BUSINESS STRATEGIC ALIGNMENT, AND IT CAPABILITY
}

\author{
Saeid Jorfi ${ }^{1}$, Khalil Md Nor ${ }^{2}$, and Lotfi Najjar ${ }^{3}$ \\ ${ }^{1}$ Universiti Teknologi Malaysia (UTM) \\ jsaeid2alive.utm.my \\ ${ }^{2}$ Universiti Teknologi Malaysia (UTM) \\ kmdnorefppsm. utm.my \\ ${ }^{3}$ University of Nebraska -Omaha, USA \\ Inajjar@unomaha.edu
}

\begin{abstract}
What seems to still be the main concern for managers in the corporate world across the globe is ITbusiness strategic alignment. This study seeks to address the research problem about the lack of alignment between IT and business strategies. Upon reviewing various literature on this subject, it was found that IT flexibility is one of the most vital factors that help sustain strategic alignment. The researcher upon having a detailed discussion on the possible areas associated with the present body of knowledge has discovered gaps in the studies that have been undertaken on strategic alignment and IT flexibility. This is because IT capability in relation to IT flexibility and strategic alignment has been ignored in the previous studies. As a result, this research proposes a relationship between IT flexibility (i.e., modularity, connectivity and compatibility), IT capability, and strategic alignment.
\end{abstract}

\section{KEYWORDS}

IT-Business strategic alignment, IT flexibility, IT capability.

\section{INTRODUCTION}

IT in business setups has undergone dramatic switches in the last few decades. All over the world, business environments have seen drastic changes as a result of the late 1990s developments in information technology. The bulk of industrial, commercial and government entities are now more dependant their IT systems. As framed in Rockart's language, as indicated by Ward and Peppard [1], "information technology has become inextricably intertwined with business". In the present business environment, the use of IT is pervasive and could lead to extended advantages in competitive situations.

The doubt then crops up as to what position is played by IT in the success of an organization's strategic objectives and goals. In reply to this, Venkatraman et al. [2] suggested that the critical function of IT is very often characterized as a match or in association with the strategic aims of the organization. A factor that increasingly worries organizations and the management about IT is and continues to be IT positioning in line with strategic aims [3], [4].

It is a very apparent fact in literature that the function of strategic positioning between IT and business policies is a vital part of an organization's performance [5], [6] and competitive 
advantage [7]. Strategic alignment has proved to enhance organizational efficacy [8], get the most out of return on investment [9], enable organizations to improve on managing their business needs on the whole, technology and rivals [10] and while offering stability to a company [11]. According to Piccoli and Ives [12], organizations such as Harrah's Entertainment, Wal-Mart and Dell have gained tremendously by aligning their IT strategies accurately with their own business strategies.

Even though strategic alignment has brought many benefits as mentioned above, there are severe challenges confronted in sustaining strategic alignments in business setups in these times. One of the primary challenges confronted by organizations are the adjustments in active and unstable business settings to sustain that strategic alignment [13]. Events like price wars, decrease in demand, new product launched by a competitor can all change business strategies as expressed by Mendelson and Pillai [14]. As a result, a more flexible IT or IT that has the ability to meet business changes is very crucial to sustain strategic alignment in business environments today [15]. Past studies have shown that flexibility in IT is an influencing aspect in sustaining strategic alignment in active and ever-changing business settings today [16], [17].

\section{IT - BUSINESS STRATEGIC ALIGNMENT}

\subsection{Importance of Strategic Alignment}

Many studies have suggested the importance of strategic alignment which is due to several reasons. Firstly, strategic alignment is effective in ensuring that areas which are critical for successful business performance are targeted by information systems (IS) [18]. Secondly, it is valuable in enhancing the understanding of top executives about the importance of IS, and simultaneously, improving the understanding of IS managers with regard to business goals [19]. Apart from that, strategic alignment is also successful in ensuring Information Strategic Planning (ISP) is in conjunction with Business Planning (BP) activities in order for IS operations to back business strategies better and participate in business value accomplishment [20]. In another study [21], strategic alignment can successfully speed up acquirement and strategic placement of IT that is in harmony with the competitive needs of the establishment as opposed to the current practice trends in the establishment.

\subsection{Definitions of Strategic Alignment}

A variety of conceptualizations and explanations are applied in the literature to explain strategic alignment. These are discussed below:

The extent to which the information technology mission, objectives, and plans support and are supported by the business mission, objectives, and plans [22], [23]. The fit between IT and business structures is defined by Jarvenpaa and Ives [24]. The association among IS strategic orientation and business strategic orientation in IS strategic alignment is explained [25]. Applying IT in an appropriate and timely way, in harmony with business strategies, goals and needs [26], [27]. The positioning of four parts, which are business strategy, IT strategy, organizational infrastructure and processes and IS infrastructure and processes in strategic alignment is stated [27]. 
International Journal of Managing Information Technology (IJMIT) Vol.3, No.1, February 2011

\section{IT FLEXIBILTY}

\subsection{Rationale for studying IT flexibility}

Mckay and Brockway [28] explained IT infrastructure as assisting the support of shared IT potential which the entire organization depends on. It is disputed that IT infrastructure should be flexible in order to be competent to cope with the growing demands of customers without increasing costs [29]. Duncan [30] established IT infrastructure-flexibility as connectivity, compatibility and modularity. Connectivity and compatibility are linked to the idea of reach and range [31], which relate to the sharing of a common set of IT resources with internal and external users. Duncan [30] defined connectivity as "the ability of any technology component to attach to any of the other components inside and outside the organizational environment". Byrd and Turner [32] stated that compatibility was "the ability to share any type of information across any technology component", and modularity was "the ability to add, modify and remove any software, hardware or data components of the infrastructure with ease and with no major overall effect". Few experimental studies tested if IT infrastructure flexibility enabled strategic alignment [33].

If an organization benefits from continuous alignment, ignoring the strategy it pursues, IT will be competent to offer the necessary support even in the case where due to increased volatility, strategy evolves or changes direction. Take the instance of airlines such as Delta and United which had earlier added low-cost carriers to their fleet. The main question was: Whether IT infrastructure could accommodate the additional booking load or if a totally new and separate infrastructure was required. Abercrombie and Fitch (a fashion retailer) were among other organizations that added distinct sports and junior clothing shops with the least effort. The underlying IT infrastructure of these stores, drawing various demographic segments and making the most of distinct brand strategies, was adaptable to the point that it could undoubtedly keep up with the needs of all stores concurrently. This flexibility has a meaning in alignment: either addition of new lines of business or increasing the capacity of business where firms increase the magnitude and scope of their strategy; therefore, IT has to be able to embrace the underlying changes in business strategy in order to provide support for it all the time [34].

Reconsidering the literature revealed the IT flexibility is the most crucial aspect of keeping up strategic alignment for today's establishments and in addition, studies in this factor are limited. Therefore, we will study the effects this factor has on alignment in this research.

\subsection{Definitions of IT flexibility}

The ability to acquire and put into operation the procedures that enhance the control of the management over the environment of the organization is defined as flexibility [35].

However, it was debated by Tallon and Kraemer [36], that IT flexibility indicates the ability to launch new resources of IT support for the organizational policies with ease and swiftness. The quick employment of technology that is facilitated with the help of IT infrastructure is IT flexibility [33]. Ness [33] mentioned that IT flexibility included three factors: Connectivity, compatibility and modularity.

In addition, Duncan [36] explained IT flexibility as being done with the help of aspects like connectivity, compatibility and modularity. She claimed that an establishment would have greater IT flexibility if it had high modularity, compatibility and connectivity. 
International Journal of Managing Information Technology (IJMIT) Vol.3, No.1, February 2011

- Compatibility: The potential to distribute a variety of information over any technological platform within the establishment is defined as compatibility [37], [38].

- Connectivity: When a technological component is capable of coordinating and communicating with any other components within the establishment as well as with the external environment, it is defined as connectivity [37]. It has been stressed by Tapscott and Caston [39] that with IT connectivity, organizations that are flawless and transparent are able to be free from the influence of time and space. It's much easier to share IT resources at the platform level with connectivity.

- Modularity: Modularity refers to the ability to easily put together by adding, modifying and removing technology components [37]. Duncan [37] mentioned that modularity is in other words, the ability to standardize business processes in order for it to be shared and reused. One example of this is structured programming and the architecture of component-based software. According to Schilling [40], modularity is described as the level or degree in which a system's component can be divided and put together again.

\subsection{Linking IT flexibility with Strategic Alignment}

What is the link between IT infrastructure flexibility and alignment? In their revolutionary study, alignment is defined by Henderson and Venkatraman [41] as an orderly relation between business strategy and IT-strategy, and between IT-strategy and IT infrastructure. Business strategy performs as the initial point in this sequence but IT infrastructure is what finally determines if the alignment will succeed or not. In the consequent study, Venkatraman, Henderson and Oldach [42] mention that competencies, both human and technological, are needed for constant alignment. On the one hand, Technical IT skills such as programming, operations, database design and the capacity to represent business knowledge or rules in technical solutions are regarded as human capabilities. On the other hand, designing and applying hardware, software and networks to accomplish a number of business requirements are thought of as technical competencies. Both of these competencies map to the four elements of IT infrastructure flexibility observed by Byrd and Turner [43] and Duncan [37] in their examining studies.

\section{LITERATURE REVIEW ON THE LINK BETEWWEN IT FLEXIBILITY AND STRATEGIC ALIGNMENT}

According to Teece, Pisano and Shuen [44], IT flexibility has an influence on strategic alignment. Weill, Subramani and Broadbent [45] also suggested the importance of IT flexibility in relation to strategic alignment and mentioned that "defender" [46], or establishments that lacked in IT flexibility, encountered a more demanding time obtaining business value from strategic alignment. Another study was carried out by Chan, Huff, Barclay and Copeland [47], when they noticed that there was a strong association between increasing innovation level-as of IT flexibility-and strategic alignment.

Tallon [34] studied six case studies in a variety of industries like aerospace, financial services, occupational services, health coverage, publishing and software firms. These industries substantiate the complication of the results. This helped him to identify a favourable association between IT infrastructure flexibility and strategic alignment. Strategic Information Systems Planning (SISP) acted as a mediator for this relationship. 
Ness's [33] thesis on measuring the associations amid IT flexibility (i.e. Connectivity, Modularity and Compatibility), strategic alignment, and the effectiveness of IT is the principal quantitative research article in the IT flexibility research stream of the literature review. The broad hypothesis that IT flexibility, strategic alignment and IT effectiveness are all favourably correlated is supported by the literature review on IT flexibility. The fallout of the research reveals that a favourable association continues to be present amid these three sections as per the following model. Moreover, the data established that IT flexibility has a stronger relationship with IT effectiveness than does strategic alignment.

As it has been mentioned previously, literature has shown that a key feature to sustain strategic alignment in the environments today is the flexibility of IT. In order to facilitate the current research, the term IT flexibility should be used to symbolize the three measurement dimensions of modularity, connectivity and compatibility as well as to characterize the construct for the operational definition provided. These aspects have been briefly explained in the following sections.

\section{IT CAPABILITY}

Enterprises consist of many different types of complex situations that are intertwined in an active and dynamic environment. The capability of IT makes it easier for companies to top their competitors and at the same time become one of the most vital sources for the enterprise. From the many studies undertaken, mainly from the United States and some of the Western countries [51], it has been found that in the $21^{\text {st }}$ century, IT capability is a crucial resource for enterprises [52].

Some of the researchers in the many Information Systems' literature have conceptualized the capability of IT from different angles. The discussion on the concept or idea of IT-capabilities has been found more commonly in practitioner-based literature rather than in academic journals. IT capability has been studied by the researchers from various viewpoints that take into account work design, power relationships, coordination and process transformation.

In one of the researches [53], IT capability is defined as a type of ability organizations have that can support the activities and work processes in the organization by arranging and bringing together other resources that are important. In another study [54], IT capability is described as the ability that can incorporate other resources of the organizations through the usage and allocation of IT resources in an organization. According to Bharadwaj [54], IT resources can be split into three groups, which are IT intangible assets, IT infrastructure and IT human resources.

When literature related to IT was examined, there were six other studies that were found to have dimensions that underlies the capability of IT construct [55], [56], [57], [58]. The ensuing dimensions that were put together from all these studies are (1) IT architecture, (2) IT infrastructure, (3) IT human resource and (4) IT relationship resource.

- IT architecture: Fertuck [59] depicted IT architecture as a design that cared for efficiency. Nonetheless, there was not only one helpful portrayal of IT architecture, but many other descriptions as well. All in all, there were a lot of diverse definitions as studies regarding the subject [60]. Only as organizations began to commit themselves to some levels of integration with the right combination of form and context did IT architecture appear slowly over time as proposed by Sullivan [61]. As a result of this, organizations decided to focus on one of the elements of information systems, which 
International Journal of Managing Information Technology (IJMIT) Vol.3, No.1, February 2011

were either storage of date, applications, communications or processing. Later researchers decided to build their methods by aiming at only one out of the four elements.

- IT infrastructure: According to Byrd and Turner [58], the worth of IT infrastructure in today's businesses is gaining significance. The growth for an effective IT infrastructure has been positioned by many organizations as one of the topmost priorities of their IT management on the whole. Building a strong IT infrastructure has risen to become the top concern in the management of IT as it was reported in Information Week [62]. In accordance with that, the two specialists in IT, Broadbent and Weill [63] have discovered that an average of 58\% of a company's funds is accounted for IT infrastructure spending. This figure has risen to around $11 \%$ a year in current years.

- IT human resources: We cannot deny the value or worth of IT to today's businesses. A valuable human asset to any organization today is an IT staff that can without fail resolve business problems and deal with opportunities using IT. As the value of IT increases in today's organizations, the mandatory skills of an IT staff will also develop to become vital. Managerial, business and interpersonal skills have also been quoted to have become obligatory together with technical skills for employees in the technical field [64], [65]. In today's modern organizations, research has put forward that those soft skills are vital to programmers, database administrators, systems analysts and other IT staff [66], [67].

- IT relationship resource: IT relationship resource is explained as the incomparable relationship between the IT and organizational units. IT management and organizational units have to share the responsibility and threats in order to have effective IT application in the organization. Trust and mutual respect along with the capability to communicate, coordinate or discuss fast and effectively are imperative for shared risk and responsibility. Proof of a powerful relationship asset comprises of business partner ownership of all IT projects along with top management leadership in setting up IT priorities. It also consists of developing users' understanding of IT's ability, and IT sourcing capacity [68].

\section{LITERATURE ON IT CAPABILITY}

IT capability has become more important in contemporary organizations with the increased emphasis on the strategic role of IT [69]. The role of IT capabilities in enhancing organizational performance is well established in the literature. A group of IT studies suggests IT capabilities provide a basis of gaining competitive advantage. IT studies have revealed that the capacity of information technology helps to gain a competitive advantage over other competitors in the business [70] and improving the functionality of the organization [71]. Detailed studies of ITcapabilities show that IT-capabilities help to collect data effectively and utilize the data in a favourable manner [69], [70]. It is argued by Floyd et al. [72] that IT-capabilities help to provide reliable service, reduce the errors in conducting business and increase consistent performance. It is also argued that capabilities can contribute to provide better quality of service with the help of improved personalized services, and in creating a knowledge bank to recognize and distribute organizational expertise [73]. Further, there are claims that [74] an organization can improve its performance with the help of IT-capabilities. This is done by eliminating 
inefficiency; lowering cost in the long run, improving the consistency of service and reducing errors in daily business transactions.

\section{RESEARCH MODEL}

Based upon the studies and researches, it can be concluded that strategic alignment is affected by many factors. To name a few factors, communication between IT and business, shared knowledge between IT and business, IT-managerial resources, flexibility of IT, environmental ambiguity, size of organization, the relationship between IT planning and business, design or planning of strategic information can influence strategic alignment. For this study, we have focused on IT flexibility due to some reasons that we have mentioned previously. By reviewing much literature, it was found that IT flexibility brought about a positive effect on strategic alignment. In relation to strategic alignment, many researchers have categorized modularity, connectivity and compatibility as components of IT flexibility. We are going to examine all the mentioned components against other constructs. Additionally, we have found a gap after examining and reviewing the literature on this subject. In order to fill in the gap, we have included IT capability construct in relation to strategic alignment and IT flexibility. We will discuss the arguments and support for the construct in more detail in next section. Figure 1 shows the research model.

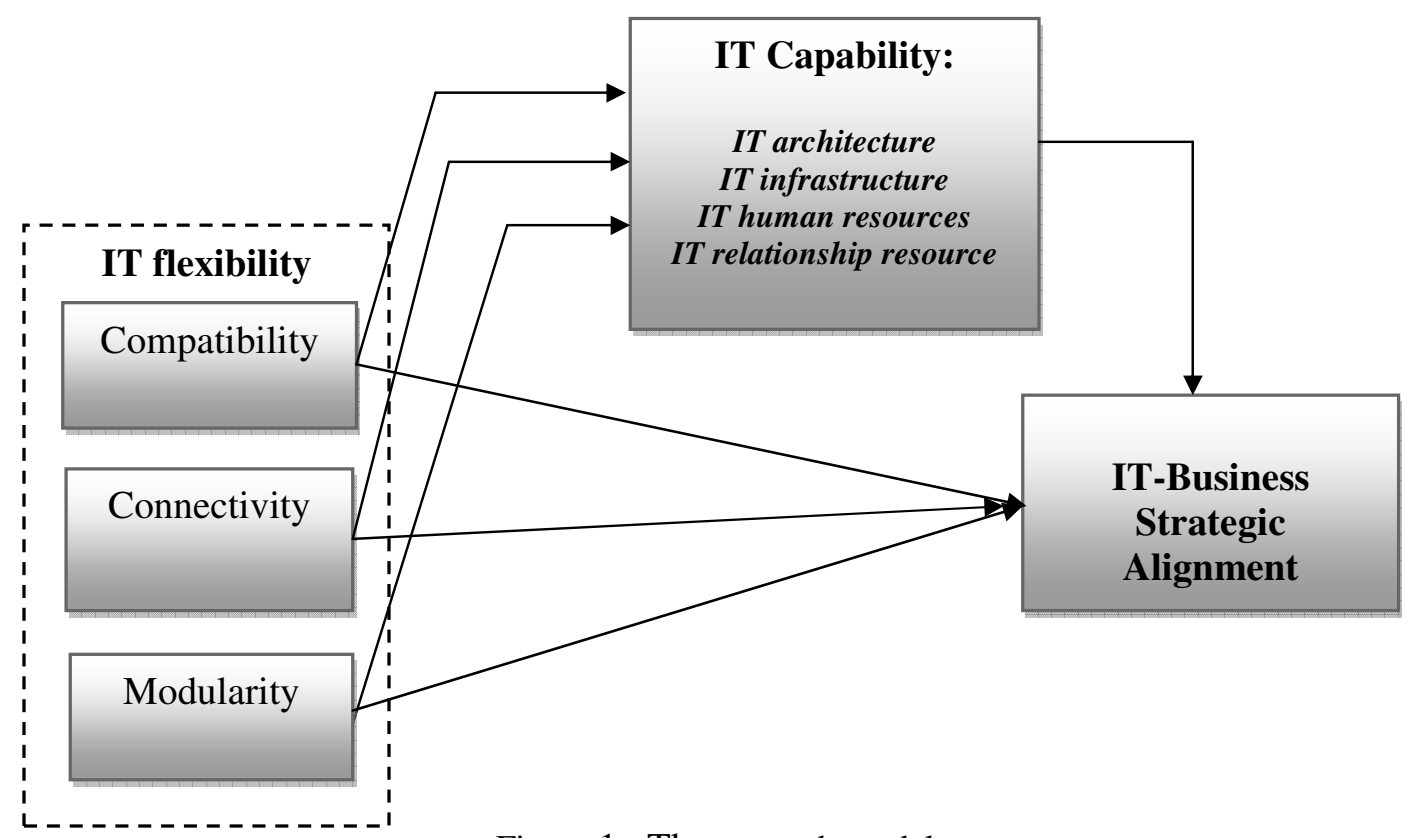

Figure 1. The research model

Like mentioned previously, there are many components and definitions for IT capabilities. In this study, we have defined IT capability as an organization's capacity to gain, position, influence its IT resources with a combination of other resources and capabilities to accomplish the objectives of the business via IT execution. We have used four dimensions, particularly IT human resource, IT relationship, IT infrastructure and IT architecture for measurement. We believe that the components that make up IT flexibility significantly influence IT capability and at the same time, IT capability also greatly influences strategic alignment. 
International Journal of Managing Information Technology (IJMIT) Vol.3, No.1, February 2011

\section{DISCCUSTION}

\subsection{The relationship between IT flexibility and IT capability}

Byrd and Turner [35] defined IT infrastructure flexibility as “...the ability to easily and readily diffuse or support a wide variety of hardware, software, communications technologies, data, core applications, skills and competencies, commitments, and values within the technical physical base and the human component of the existing IT infrastructure".

To put it simply, IT-capabilities that include data, fundamental applications, technologies for communications, data, hardware and software, the human factor and expertise in IT infrastructure are supported by IT flexibility. In the past, to adjust to the fast transforming business environment, IT infrastructure is seen to be essential.

For information systems to be successful flexibility is the key and the information systems have to be able to accommodate some degree of change, bearing in mind the needs of the business processes that are being supported. One of example of this is of an electronic procurement system. In order for the electronic procurement to process real request of purchase, it has to have a logical amount of product classifications or groupings and steps for approval.

When there is not enough flexibility, the effectiveness of an information system is contained This is so because the lack of flexibility stops it from being used in some conditions and makes exemptions of important handling. To make matters worse, the lack of flexibility decreases the duration or life of systems especially in situations where it stops the systems from making any changes. This is happens because it needs to accommodate the business processes that are being supported.

Business application has been made part of IT infrastructure by a few studies (see e.g. [63], [32], [30]). Duncan [30] dealt with business applications in her study. She stressed that firms were able to create applications that could intently fulfil the aims of business with flexible IT infrastructure.

The observation made by Duncan [30] shows that in some scenario's the IT infrastructure of a certain establishment may help to facilitate planned advancement in business processes. In other cases, the IT infrastructure may not facilitate the same innovations in business processes. She referred to this characteristic as IT infrastructure flexibility and suggested that both business and IT application development capabilities reflect the flexibility of infrastructure components. She suggested that infrastructure flexibility improves systems developers' ability to design and build systems to meet organizational business objectives.

\subsubsection{The relationship between compatibility and IT capability}

Information has to be distributed and shared across various technological platforms within the business establishment. This ability to distribute the information in the organization is known as Compatibility [30], [31]. IT compatibility not only assists to extend the boundaries of the establishment, but it also makes the employees more powerful. Information Technology Compatibility also makes sure that information and data is available at all times within the corporate establishment [39]. Due to the availability of knowledge and information at all times, IT capabilities including IT Human Resource, IT Relationship Resource and IT architecture can be supported with the help of compatibility. Compatibility can also maintain the IT infrastructure. This is possible as the organization is capable of sharing any form of information across any technological platform. 
International Journal of Managing Information Technology (IJMIT) Vol.3, No.1, February 2011

\subsubsection{The relationship between connectivity and IT capability}

Duncan [30] has defined connectivity as the ability of every part or component of technology to communicate or interact with any other exterior and interior components in the environment of the organization. To put it simply, when all applications, functional areas, persons in the organization are linked to each other, you have connectivity. It has been stressed by Tapscott and Caston [39] that with IT connectivity, organizations that are flawless and transparent are able to be free from the influence of time and space. It's much easier to share IT resources at the platform level with connectivity. Therefore, the level or communications all through the organization is greatly improved and this makes it easier for users all across the borders of the organization to impart information at fast speed. As a result, our findings imply that connectivity performs a part in the scope of IT capabilities.

\subsubsection{The relationship between modularity and IT capability}

Duncan mentioned that modularity is the ability to standardize business processes in order for it to be shared and reused. One example of that is structured programming and the architecture of component-based software. According to Schilling [40], modularity is described as the level or degree in which a system's component can be divided and put together again. In other words, modularity is the ability to create or make changes fast to the business applications in order to deal with new business settings. An example of this is middleware that has been modularized and which provides the ability to exchange and make information available to us through a variety of applications, especially between modern or fresh applications and legacy applications throughout an organization.

When there is a greater level of modularity, then there is better speed of newer applications being developed or modification of current applications. As a result, we can conclude that, modularity supports IT-capabilities that comprises of IT infrastructure.

\subsection{The relationship between IT flexibility and Strategic Alignment}

IT-business strategic alignment refers to the extent to which the IT mission, objectives, and plans support, and are supported by, the organization's mission, objectives, and plans [56]. This alignment creates an integrated organization in which every function, unit, and person are focused on the organization's competitiveness.

There are many literatures that explain the favourable effect of IT flexibility on strategic alignment. As mentioned by Teece, Pisano and Shuen [44], strategic alignment is impacted by the flexibility of information technology. Chung et al. [17] put forward a case study which considered the components of information technology flexibility. These components were previously defined. This case study also considered the effect of these components on the success of the alignment between the Information Technology and the organization's strategy. These four components are: Connectivity, modularity, IT personnel and compatibility.

Beneficial, extraordinary, non substitutable and stationary resources are viewed as the crucial judge of enhanced performance by many resource-based theories. However, it is argued by these theories that organizations with adaptable infrastructure of information technology have a higher probability to keep up with the struggle between organizational policies and information technology. This is due to the fact that such organizations with more adaptable IT infrastructure are in a better position to redirect information technology around the value chain in order to maintain a change in the business strategy [34]. 
In order to support the above literature, a quantitative study was presented by Ness [33]. This study needed him to measure the relationship between IT flexibility, strategic alignment and the effectiveness of Information Technology. In addition, it was further noted by Ness that the flexibility of Information Technology can be ascertained with the help of three distinct dimensions. These dimensions are connectivity dimension, compatibility dimension and modularity dimension.

\subsection{The relationship between IT capability and Strategic Alignment}

As mentioned earlier, the two very important elements of IT capability in this study are IT relationship resource and IT human resources. It has been described that IT relationship is like a relationship that is beyond any comparison between IT and the organization. We have described IT relationship in this study as the brilliance in communication, negotiation, coordination on either sides of the relationship, plus a considerable amount of shared knowledge on the abilities of information technology and the requirements of the business. Additionally, in this study, IT human resource is characterized as knowledge of business, solving problem, technical skills and planning.

These concepts are related to each other, for example the support provided to Information Technology human resource by Information Technology relationship in general. Important features like communication, sharing domain knowledge, skills and relationship management are some of the important features of IT-capabilities that are involved. The section below explains the features with regard to strategic alignment.

The degree to which business executives and IS spend time and work in dealing with the relationship with one another is described as relationship management. According to Rockart et al. [67] the closeness of the relationship between business executives and IS makes it possible for them to work jointly in better understanding of the technological and business needs of the organization. It is perceived by Ross et al. [57] that a good relationship between IT and business is one of the most important assets of IT.

When there is a good relationship between the CEO and CIO, it makes it possible for ISbusiness planning integration to happen [68]. As a result of this relationship, the ability of IT to add to the business's worth will increase. This will also guarantee that the integration of IT and business strategies will be a success [67].

There have also been a few other researchers in the literature who have put forward the fact that having a good relationship between IT executives and the business will enhance the level of communication [67]. It has been observed by Rockart et al. [67] that only by having strong relationships between executives and IT staff will the much needed communication take place. For the alignment to work well, informal relationship networks play a vital part [8]. On the whole, the relationship between business and IT is seen as a vital factor in making strategic alignment possible.

In order to carry out a task that is vital in an organization, the skill needed is the skill to perform processing in an efficient and effective way that is fitting for the particular job. Skills that are gained can come from mentoring, training and practice. Competency is attained to succeed at a specific job when skills are well-sharpened, resulting in improved level of output and accomplishment for a business [13].

This distinctive skill or ability to carry out a given job at a satisfactory level is the most sought after trait that businesses can encourage attaining and sustaining competitiveness. Realizing 
business aims becomes easier when this trait is achieved. As a result of attaining this trait, the time and work spent by an organization can be a significant feature leading to the organization aligning its business to achieve its goals. Skills that involve IT, managerial and business has an impact on strategic alignment as shown by some researchers (e.g. [34])

Another important aspect of IT capability is IT infrastructure that we explain with regard to strategic alignment in the following.

Huge establishments like Wal-Mart and K-mart made new demands on the company like costcutting and just-in-time replacement of stock. With these demands increasing in the early 1990s, Johnson and Johnson faced new challenges in business. The business managers and the managers of Information Technology (IT) in Johnson and Johnson acted in alliance to develop a new set of Information Technology (IT) infrastructure capabilities. These capabilities facilitated the organization to offer the required services for its big customers and at the same time cut expenditures for the organization [63]. In the late 1990s, Charles Schwab not only concentrated on delivering on time, but also focused on personalized information. With the help of the organization's Information Technology infrastructure and its applications associated with its business focus, Schwab became a complete service brokerage firm. The organization was in a position to offer information and at the same time process transactions in meeting the goals of the organization. Through Schwab's web site, customers were able to retrieve stock quotations and at the same time place their orders too. These two examples reveal that not only can substantial benefits be provided with the help of the organizations IT infrastructure, but also it can also help to continue business practices.

Strategic Alignment Model (SAM) is one of the research models that has been widely discussed by many scholars. The relationship between the four domains that includes business strategy, IT strategy, IT infrastructure and processes and organizational infrastructure and processes is described in SAM, which was built by Henderson and Venkatraman [40]. Inter-connected collections of decisions are contained inside these domains. With regards to business strategies in SAM, it comprises the scope of business such as the market or product opportunities, unique expertise and business management like the options on structural mechanism for managing the business. In describing the IT choices, the extent of IT capacity, complete expertise like the dependability of system and its interconnectivity and IT management. Organizational infrastructure and processes deals with the management of infrastructure, business processes like workflow and the organizational expertise. Last but not least, IT infrastructure and the process is described, and this has the attributes of IT infrastructure, IT expertise and IT processes.

As argued above, relationship between IT and business, human resource skills, IT infrastructure influence strategic alignment and as stated earlier, these aspects are the most important factors of IT capability. As a result, IT capability has a positive impact on strategic alignment.

\section{CONCLUSION}

Upon reviewing various literatures on this subject, it was found that IT flexibility is one of the most vital factors that helps sustain strategic alignment in today's environments, but unfortunately the studies on this subject is very limited. At present, organizations are looking at IT flexibility as the main and fundamental competency that is required in order for organizations to exist and grow in the present-day environments. Also, reviewing the literature showed that modularity, connectivity and compatibility are the most important dimensions of IT flexibility. The researcher upon having a detailed discussion on the possible areas associated with the present body of knowledge has discovered gaps in the studies that have been done on strategic 
International Journal of Managing Information Technology (IJMIT) Vol.3, No.1, February 2011

alignment and IT flexibility. This is because, IT capability in relation to IT flexibility and strategic alignment have been ignored in the prior studies. To fill this gap, it is argued that ITcapability influenced by dimensions of IT flexibility (i.e., modularity, connectivity and compatibility) and influences strategic alignment. As a result, this research proposes the relationships between IT flexibility (i.e., modularity, connectivity and compatibility), ITcapability and strategic alignment.

\section{REFERENCES}

[1] Ward, J. \& Peppard, J. (2002) Strategic planning for information systems, West Sussex, England: John Wiley \& Sons.p.1.

[2] Venkatraman, N., Henderson, J. C., \& Oldach, S. (1993) Continuous strategic alignment: Exploiting information technology capabilities for competitive success. European Management Journal, 11(2), 139-149.

[3] Galliers, R.D. (1993) IT strategies: beyond competitive advantage. Journal of Strategic Information Systems, 2, 4, 283-291.

[4] Computer Sciences Corporation (CSC). (2001) Critical Issues in Information Systems Management. Cambridge, MA.

[5] Brown, I.T.J. (2004) Testing and extending theory in strategic information systems planning through literature analysis. Information Resources Management Journal, 17, 4, $20-48$.

[6] Kearns, G.S., Lederer, A. (2001) Strategic IT alignment: A model for competitive advantage. Proceedings of the 22nd International Conference on Information Systems.

[7] Grant, R.M. (1991) the resource-based theory of competitive advantage: implications for strategy formulation. California Management Review (spring), 114-135.

[8] Chan, Y.E., Huff, S.L. (1993) Strategic information systems alignment. Ivey Business Quarterly, 51-55.

[9] Feidler, K.D., Gorver, V., \& Teng, J.T.C. (1995) an empirical study of information technology enabled business process redesign and corporate competitive strategy. European Journal of Information Systems, 4(1), 17-30.

[10] Boar, B.H., AT\&T Bell Laboratories (1994) Practical steps for aligning information technology with business strategies - How to gain a competitive advantage (1st edition). New York: John Wiley \& Sons, Inc.

[11] Labovitz, G., Rosansky, V. (1997) the power of alignment: How great companies stay centered and accomplish extraordinary things. NY: John Wiley \& Sons, Inc.

[12] Piccoli, G., and Ives, B. (2005) Review: IT-dependent strategic initiatives and sustained competitive advantage: a review and synthesis of the literature. MIS Quarterly, 29, 4, 747-776.

[13] Luftman, J.; Papp, R.; and Brier, T. (1999) Enablers and inhibitors of business-IT alignment. Communications of AIS, 1, 11, 1-32.

[14] Mendelson, H., and Pillai, R.R. (1998) Clockspeed and informational response: evidence from the information technology industry. Information Systems Research, 9, 4, 415433.

[15] Bharadwaj, A.S. (2000) a resource-based perspective on information technology capability and firm performance: An empirical investigation. MIS Quarterly, 24, 1, 169-196.

[16] Ness, L.R. (2005) assessing the relationships among IT flexibility, strategic alignment and IT effectiveness: study overview and findings. Journal of Information Technology Management, 16, 2, 1-17. 
International Journal of Managing Information Technology (IJMIT) Vol.3, No.1, February 2011

[17] Chung, S.H.; Rainer, R.K., Jr.; and Lewis, B.R. (2003) the impact of information technology infrastructure flexibility on strategic alignment and applications implementation. Communications of AIS, 11, 191-206.

[18] Das, S.R.; Zahra, S.A.; and Warkentin, M.E. (1991) Integrating the content and process of strategic MIS planning with competitive strategy. Decision Sciences, 22, 5, 953-984.

[19] Newkirk, H.E., and Lederer, A.L. (2006) Incremental and comprehensive strategic information systems planning, in an uncertain environment. IEEE Transactions on Engineering Management, 53, 3, 380-394.

[20] Teo, T.S.H., and King, W.R. (1997) Integration between business planning and information systems planning: an evolutionary-contingency perspective. Journal of Management Information Systems, 14, 1, 185-214.

[21] Bowman, B.J.; Davis, G.B.; and Wetherbe, J.C. (1983) Three stage model of MIS planning. Information \& Management, 6, 3, 11-25.,

[22] King, W.R. (1978) Strategic planning for management information systems. MIS Quarterly, 2, 1, 27-37.

[23] Reich, B.H., and Benbasat, I. (2000) Factors that influence the social dimension of alignment between business and information technology. MIS Quarterly, 24, 1, 81-113.

[24] Jarvenpaa, S.L., and Ives, B. (1993) Organizing for global competition: The fit of information technology. Decision Sciences, 24, 3, 547-580.

[25] Chan, Y.E.; Huff, S.L.; Barclay, D.W.; and Copeland, D.G. (1997) Business strategic orientation, information systems strategic orientation, and strategic alignment. Information Systems Research, 8, 2, 125-150.

[26] Luftman, J.; Papp, R.; and Brier, T. (1999) Enablers and inhibitors of business-IT alignment. Communications of AIS, 1, 11, 1-32.

[27] Luftman, J.N.; Lewis, P.R.; and Oldach, S.H. (1993) Transforming the enterprise: the alignment of business and information technology strategies. IBM Systems Journal, 32, 1,198221.

[28] McKay, D., and Brockway, D. (1989) building IT infrastructure for the 1990s. Stage by Stage, 9 (3), 1-11.

[29] Weill, P.(1993) The role and value of information technology infrastructure: some empirical observations. In R. Banker, Kaufman, R., M.A. Mahmood. (Eds). Strategic information technology management: perspectives on organizational growth and competitive advantage. Middleton, PA: Idea Group Publishing.

[30] Duncan, N. (1995) Capturing flexibility of information technology infrastructure: A study of resource characteristics and their measure. Journal of Management of Information Systems, 12 (2), 37-57.

[31] Keen, P.G. (1991) Redesigning the Organization through Information Technology. Planning Review, 19 (3), 4-9.

[32] Byrd, T., and Turner, E. (2000) an exploratory analysis of the information technology infrastructure flexibility construct. Journal of Management Information Systems, 17 (1), p. 172.

[33] Ness, L.R. (2005) assessing the relationships among IT flexibility, strategic alignment, and IT effectiveness: study overview and findings. Journal of Information Technology Management, XVI (2), 1-17. 
International Journal of Managing Information Technology (IJMIT) Vol.3, No.1, February 2011

[34] Tallon, P.P. (2009) how information technology infrastructure flexibility shapes strategic alignment. Planning for information systems, M.E. Sharpe, Inc.

[35] Byrd, T. A., \& Turner, D. E. (2000) Measuring the flexibility of information technology infrastructure: Exploratory analysis of a construct. Journal of Management Information Systems, 17(1), 167-208..

[36] Tallon, P.P., Kraemer K.L. (2003) Investigating the relationship between strategic alignment and IT business value: The discovery of a paradox. University of California, Irvine., Retrieved March 12, 2004, from

http://www.crito.uci.edu/publications/pdf/Alignmen tParadox.pdf

[37] Duncan, N. B.(1995) Capturing flexibility of information technology infrastructure: A study of resource characteristics and their measure. Journal of Management of Information Systems, 12(2), 37-57. 195.

[38] Keen, P.G. (1991) Redesigning the Organization through Information Technology. Planning Review, 19 (3), 4-9.

[39] Tapscott, D. and Caston, A.(1993), Paradigm shift: The new promise of information technology. McGraw-Hill. New York, NY.

[40] Schilling, M.A.(2000) toward a general modular systems theory and its application to interfirm product modularity. Academy of Management, 25(2), 312-334.

[41] Henderson, J.C., and Venkatraman, N.(1993) Strategic alignment: leveraging information technology for transforming organizations. IBM Systems Journal, 32, 1, 4-16.

[42] Venkatraman, N.; Henderson, J.C.; and Oldach, S.H. (1993) Continuous strategic alignment: exploiting IT capabilities for competitive success. European Management Journal, 11, 2, 139-149.

[43] Byrd, T.A., and Turner, D.E. (2000) Measuring the flexibility of information technology infrastructure: exploratory analysis of a construct. Journal of Management Information Systems, 17, 1, 167-208.

[44] Teece, D.; Pisano, G.; and Shuen, A. (1997) Dynamic capabilities and strategic management. Strategic Management Journal, 18, 7, 509-533.

[45] Weill, P.; Subramani, M.; and Broadbent, M. (2002) Building IT infrastructure for strategic agility. Sloan Management Review, 44, 1, 57-65.

[46] Miles, R.E., and Snow, C.C. (1978) Organizational Strategy, Structure, and Process. New York: McGraw-Hill.

[47] Chan, Y.E.; Huff, S.L.; Barclay, D.W.; and Copeland, D.G. (1997) Business strategy orientation, information systems orientation and strategic alignment. Information Systems Research, 8, 2, 125-150.

[48] Porter, M.E.(1996) What is strategy? Harvard Business Review, 74, 6, 61-77.

[49] Tallon, P.P., Kraemer K.L.(2003a) Investigating the relationship between strategic alignment and IT business value: The discovery of a paradox. University of California, Irvine. Retrieved March 12, 2004, from http://www.crito.uci.edu/publications/pdf/AlignmentParadox.pdf

[50] Byrd, T., Turner, D. (2000) Measuring the flexibility of information technology infrastructure: Exploratory analysis of a construct. Journal of Information Systems Management, 17(1), 167-208.

[51] Tippins, Michael J. \& Ravipreet S. Sohi.(2003) IT competency and firm performance: Is organizational learning a missing link? Strategic Management Journal, 24(8): 745-61.

[52] Bharadwaj, Anandhi S., V. Sambamurthy, \& Robert W. Zmud.(1999) IT Capabilities: theoretical perspectives and empirical operationalization. Paper presented at $20^{\text {th }}$ International Conferences on Information Systems, Charlotte, NC. 
International Journal of Managing Information Technology (IJMIT) Vol.3, No.1, February 2011

[53] Lee TW, Girolami M, Sejnowski TJ.(1999) Independent component analysis using an extended infomax algorithm for mixed sub-Gaussian and super-Gaussian sources. Neural Comput;11:417-41.

[54] Tuli, K.R., Kohli, A. K. and Bharadwaj, S. G. (2007) Rethinking Customer Solutions: From Product Bundles to Relational Processes, Journal of Marketing, Vol. 71, no. 3, pp. 1-17.

[55] Sabherwal, Rajiv \& Peeter. Kirs. (1994) the alignment between organizational critical success factors and information technology capability in academic institutions. Decision Sciences, 25(2): 301-31.

[56] Sabherwal, Rajiv. (1999) the relationship between information system planning sophistication and information system success: An empirical assessment. Decision Sciences, 30(1): 137-68.

[57] Ross, Jeanne W, Cynthia Mathis Beath, \& Dale L. Goodhue. (1996) Develop long-term competitiveness through IT assets. Sloan Management Review, 38(1): 31-33.

[58] Byrd, Terry Anthony \& Douglas E. Turner. (2000) measuring the flexibility of information technology infrastructure: Exploratory analysis of a construct. Journal of Management Information Systems, 17(1): 167-208.

[59] Fertuck, L. (1992) Systems Analysis and Design: With CASE Tools, Wm. C. Brown Communications Inc., Dubuque, Iowa.

[60] Gibson, Rick. (1994) Global information technology architectures. Journal of Global Information Management, 2(1): 28-39.

[61] Sullivan, C.H., Jr. (1982) Rethinking computer systems architecture. Computerworld extra, XVI: 5-10.

[62] InformationWeek. (1999) Bond the new and the old: enterprise architecture, InformationWeek.

[63] Broadbent, Marianne \& Peter Weill. (1997) Management by maxim: how business and IT managers can create IT infrastructures. Sloan Management Review, 38(3): 77-83.

[64] Couger, J.D., G.B. Davis, D.G. Dologite, D.L. Feinstein, J.T. Gorgone, A.M. Jenkins, G.M. Kasper, J.C. Little, H.E. Longenecker, \& J.S. Valacich. (1995) IS '95: Guideline for undergraduate IS curriculum. MIS Quarterly, 19(3): 341-60.

[65] Lee, Denis M S, Eileen M Trauth, \& Douglas. Farwell.(1995) Critical skills and knowledge requirements of IS professionals: A joint academic/industry investigation. MIS Quarterly, 19(3): 313-41.

[66] Cheney, P.H., D.P. Hale, \& G.M. Kasper.(1989) Information systems professionals: skills for the 1990s. Paper presented at Proceedings of the 22nd Annual Hawaii International Conference on Systems Science.

[67] Rockart, John F, Michael J Earl, \& Jeanne W. Ross.(1996) Eight imperatives for the new IT organization. Sloan Management Review, 38(1): 43-56.

[68] Feeny, David F. \& Leslie P. Willcocks. (1998) Re-designing the IS function around core capabilities. Long Range Planning, 31(3): 354-67.

[69] Bharadwaj, Anandhi S., V. Sambamurthy, \& Robert W. Zmud. (1999) IT Capabilities: theoretical perspectives and empirical operationalization. Paper presented at $20^{\text {th }}$ International Conferences on Information Systems, Charlotte, NC.

[70] Bharadwaj, Anandhi S., (2000) A Resource-based perspective on information technology capability and firm performance: An empirical investigation. MIS Quarterly, 24(1): 169-96.

[71] Santhanam, Radhika \& Edward Hartono. (2003) Issues in linking information technology capability to firm performance. MIS Quarterly, 27(1): 125-53. 
[73] Quinn, J. B., and Hilmer, F. G. (1994) Strategic Outsourcing, Sloan Management Review (35:4), pp. 43-55.

[74] Tippins, Michael J. \& Ravipreet S. Sohi. (2003) IT competency and firm performance: Is organizational learning a missing link?

Strategic Management Journal, 24(8): 745-61.

\section{Authors}

SaeidJorfi is a PhD student in IT Management at Universiti Teknologi Malaysia, Malaysia. His research interests are in the area of IT flexibility, IT capability, IT-Business strategic alignment, IT strategic planning, and IT effectiveness. He has published over 40 papers in refereed journals and conference proceedings. Saeid Jorfi has over 15 years of experience working in e-banking field and held positions as an e-banking Expert and Manager. Additionally, he has over 7 years of University teaching experience.

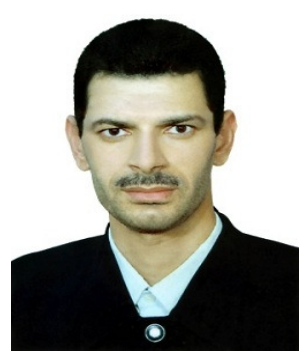

Khalil Md Nor is Associate Professor at Universiti Teknologi Malaysia, Malaysia. He is a member of the Management Department, Faculty of Management and Human Resource Development. He received his Ph.D. in Management Information Systems from Southern Illinois University Carbondale. He has published articles in Journal of Internet Commerce, Journal of Information Systems and Technology Management, Journal of Internet Banking and Commerce, International Journal of Economics and Management and Chinese Management Studies. His research interests are in the area of technology adoption and ecommerce.

Lotfi Najjar is an Associate Professor in the Department of Information Systems and Quantitative Analysis in the College of Information Science and Technology at the University of Nebraska at Omaha. He holds a Ph.D. in Industrial and Management Systems Engineering with supporting areas in MIS, and Operations Management from university of NebraskaLincoln. His research interests are in the areas of Quality Information Systems (Data Quality), Business Process Reengineering \& IT, Software Quality and Reliability, System Quality, and Total Quality Management (TQM) \& IT in both service and manufacturing industries. Najjar's teaching interests are in Quality Information Systems, Business Process Reengineering \& IT, Business Data Communications, Introduction to Management Information System, Quality Control, Production and Operations Management, Statistics, and Mathematics. He has been with UNO since 1989. 